\title{
ТЕХНОЛОГІЧНЕ ЕЛЕКТРООБЛАДНАННЯ
}

УДК $621.365 .5: 004.94$

\section{ЭЛЕКТРОМАГНИТНЫЕ, ТЕПЛОВЫЕ И ГИДРОДИНАМИЧЕСКИЕ ПРОЦЕССЫ ПРИ ИНДУКЦИОННОМ НАГРЕВЕ ВЫХОДНОГО КАНАЛА СТЕКЛОВАРЕННОЙ ПЕЧИ}

И.В. Волков, чл.-корр. НАН Украины, А.Д. Подольцев, докт. техн. наук,

И.Н. Кучерявая, докт. техн. наук

Институт электродинамики НАН Украины,

пр. Победы, 56, Киев-57, 03680, Украина

ig.volkov@ukr.net

Разработана и реализована математическая модель взаимосвязанных электромагнитных, гидродинамических и тепловых прочессов при индукционном нагреве выходного канала стекловаренной печи. Трехмерная модель и созданная на ее основе компьютерная методика позволяют определять оптимальные режимы нагрева расплавленного стекла путем выбора расположения индуктора и его параметров, достигая при этом требуемой температурной однородности расплава и его высокого качества. Библ. 17, рис. 7, таблица.

Ключевые слова: электромагнитные, тепловые и гидродинамические процессы, мультифизические задачи, индукционный нагрев, расплавленное стекло, выходной канал стекловаренной печи, компьютерное моделирование.

Введение. Стекольное производство включает выработку листового, сортового стекла и стеклянных изделий с помощью стекловаренных печей $[1,2]$. В технологическом процессе изготовления изделий из стекла происходят плавление сырья (шихты) и варка жидкого стекла в печах при высоких температурах (до $2000^{\circ} \mathrm{C}$ ).

Электрическая варка является перспективным способом производства различных видов стекол и имеет достаточно широкое распространение [3-6]. Она предполагает подвод электрического тока к расплаву с помощью контактов (через молибденовые или графитовые электроды). При этом происходит нагрев и варка стекла.

Электрические печи по сравнению с другими видами печей имеют ряд преимуществ меньшие размеры, бо́льшая производительность, экономичность, экологичность, простота регулируемости. Коэффициент полезного действия электрических печей достигает 50-60\%.

Стекольные заводы в Украине для нагрева и плавления сырья используют исключительно природный газ [7]. В условиях высокого уровня потребления газа (до 3 млрд.куб.м в год) перевод промышленных стекловаренных печей на питание электроэнергией представляется важным шагом в экономическом и энергетическом плане.

В Институте электродинамики НАН Украины созданы теоретические основы использования электроэнергии (вместо газа) в стекловаренных печах и принципы разработки электротехноло-

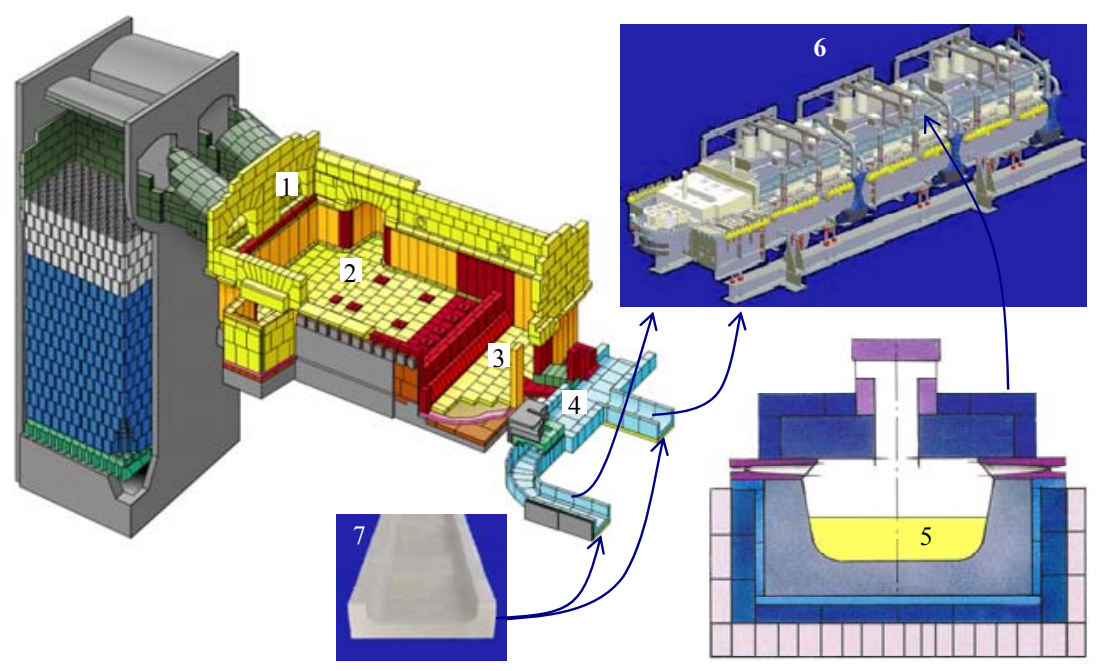

Рис. 1 
гического оборудования для реализации нагрева в печах стекломассы. Предлагаемый метод основан на индукционном нагреве стекла, в том числе на одном из последних этапов производства - в выработочных каналах, после которых либо вытягивается листовое стекло, либо изготавливаются стеклоизделия.

На рис. 1 показана регенеративная стекловаренная печь, представляющая собой наиболее распространенный тип крупных непрерывно действующих печей для стекольного производства. Шихта загружается в печь через загрузочный карман (1) в торце варочной части (2). Под воздействием высокой температуры шихта превращается в расплавленную стекломассу, которая сначала движется в студочную часть (3), где обеспечивается снижение температуры расплава до необходимой для выработки изделий. После этого происходит распределение (4) стекломассы (5) по выработочным каналам (6) и ее продвижение по рабочим концам каналов (7) вплоть до линии окончательного производства из расплава готовых стеклоизделий.

На этапе выхода расплавленной стекломассы из рабочих каналов распределение температуры в ее объеме должно быть как можно более равномерным [8]. Для оценки степени однородности температуры на выходе из выработочных каналов вводится показатель термической однородности, который рассчитывается по результатам прямых измерений и может достигать 95\% [8].

Объектом исследования данной работы являются взаимосвязанные электромагнитные, тепловые и гидродинамические процессы в выработочном канале, по которому проходит расплавленная стекломасса на завершающем этапе стекловарения и в котором используется дополнительный нагрев стекла индуцированными токами среднего диапазона частоты.

Применению дополнительного электронагрева стекломассы посвящены, например, работы $[5,6]$, в которых излагается теория пламенно-электрической варки стекла. Показано, что использование дополнительного электронагрева в печах позволяет снизить удельный расход тепла, улучшить качество стекломассы. Вопросы гомогенизации расплавленного стекла в стекловаренных печах изложены в $[5,6,8]$. Теплообменные процессы и температурные режимы стекловаренных печей исследуются в работах $[9,10]$. Компьютерное моделирование трехмерных гидродинамических процессов, тепловых потоков и температурного поля в объеме всей стекловаренной печи выполняется в статьях $[11,12]$ - для газовой печи и в [13] - для электропечи.

Целью настоящей работы является создание математических основ и средств компьютерного моделирования для нахождения оптимальных режимов индукционного нагрева стекломассы, непрерывно движущейся в выходном канале стекловаренной печи.

Проводится компьютерное моделирование и численное исследование мультифизичесих процессов (электромагнитных, тепловых и гидродинамических), оказывающих влияние на потоки жидкого стекла и его нагрев до заданной температуры. В разработанной модели учитываются различные механизмы передачи тепла - за счет теплопроводности и конвекции.

Математическая модель. Исследуются связанные электромагнитные, гидродинамические и тепловые процессы в области выходного участка стекловаренной печи - в фидерном канале, показанном на рис. 2.

Рис. 2 имеет обозначения: 1 - выработочный канал; 2 - "утеплитель" (термоизолятор); 3 - крышка канала; 4 - расплавленная стекломасса; 5 - воздушная среда; 6 - спиральный индуктор. Справа показана расчетная область задачи, состоящая из $1 / 2$ канала в силу его сим-
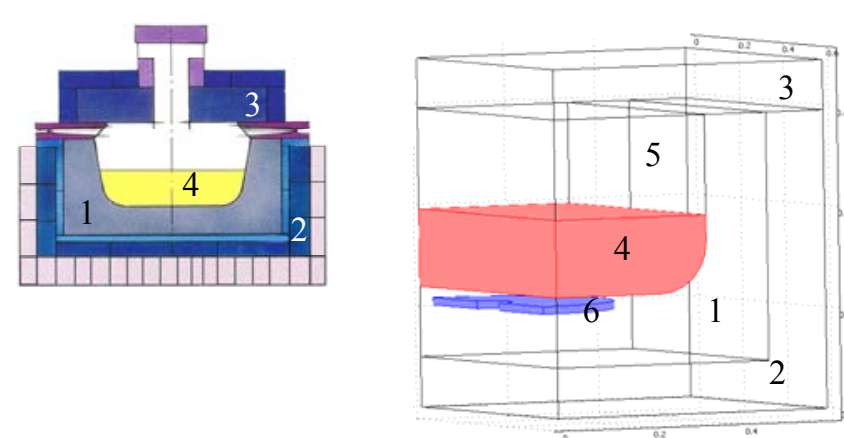

Рис. 2 метрии.

Непосредственно под каналом с движущимся расплавленным стеклом размещен индуктор, по которому протекает переменный ток. Частота и плотность тока предполагаются заданными.

Для исследования электрофизических процессов строится трехмерная математическая модель в декартовой системе координат относительно переменных - комплекс- 
ного магнитного потенциала $\dot{\mathbf{A}}=\left(\dot{A}_{x}, \dot{A}_{y}, \dot{A}_{z}\right)$, скорости движения стекла $\mathbf{v}=\left(v_{x}, v_{y}, v_{z}\right)$ и его температуры $T=T(x, y, z)$. Рассматривается случай установившегося движения расплава в канале.

Электромагнитная задача определяется уравнениями относительно векторного потенциала, формируемыми различно для различных подобластей (показанных на рис. 2):

$$
\begin{aligned}
j \omega \sigma \dot{\mathbf{A}}+\nabla \times\left(\mu_{0}{ }^{-1} \nabla \times \dot{\mathbf{A}}\right)=0 & \text { в области стекломассы (4); } \\
\nabla \times\left(\mu_{0}{ }^{-1} \nabla \times \dot{\mathbf{A}}\right)=\dot{\mathbf{J}}_{0} & \text { в области индуктора (6); } \\
\nabla \times\left(\mu_{0}{ }^{-1} \nabla \times \dot{\mathbf{A}}\right)=0 & \text { в остальных подобластях. }
\end{aligned}
$$

В системе уравнений (1) - (2): $\sigma$ - электропроводность расплавленного стекла; $\omega-$ угловая частота; $\mu_{0}$ - магнитная проницаемость вакуума; $\dot{\mathbf{J}}_{0}-$ вектор плотности тока в индукторе; $j$ - мнимая единица.

В качестве граничных условий задачи задается условие симметрии вдоль вертикальной плоскости симметрии; на внешних границах - условие магнитной изоляции $\mathbf{n} \times \dot{\mathbf{A}}=0$ ( $\mathbf{n}$ - единичный вектор внешней нормали к рассматриваемой границе). Отметим, что движение стекломассы в электромагнитной задаче не учитывается, т. к. скорость ее мала и состав-

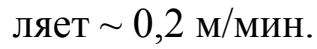

Гидродинамическая задача. Течение расплавленного стекла в канале в стационарном режиме описывается уравнениями для несжимаемой жидкости [14]:

$$
\begin{gathered}
\rho(\mathbf{v} \cdot \nabla) \mathbf{v}=\nabla \cdot\left[-p \mathbf{I}+\eta\left(\nabla \mathbf{v}+(\nabla \cdot \mathbf{v})^{T}\right)\right]+\mathbf{F}, \\
\nabla \cdot(\rho \mathbf{v})=0 .
\end{gathered}
$$

Первое уравнение представляет собой уравнение Навье-Стокса, второе - уравнение неразрывности. Неизвестными являются: $\mathbf{v}$ - вектор скорости и $p$ - давление расплава. Кроме того в (4)-(5) $\eta$ обозначает динамическую вязкость расплавленного стекла; $\rho$ - его плотность; $\mathbf{I}$ - единичный тензор; $\mathbf{F}=\left(F_{x}, F_{y}, F_{z}\right)$ - объемная плотность электромагнитных сил, определяемая как

$$
\mathbf{F}=\operatorname{Re}[\dot{\mathbf{J}} \times \stackrel{*}{\mathbf{B}}],
$$

где $\dot{\mathbf{J}}=-j \omega \sigma \dot{\mathbf{A}}-$ вектор плотности индуцированного тока в расплаве; $\dot{\mathbf{B}}=\operatorname{rot} \dot{\mathbf{A}}-$ вектор магнитной индукции; Re обозначает действительную часть комплексной величины, "*" комплексно-сопряженную величину.

Граничные условия гидродинамической задачи определяются следующим образом. На входной поверхности задается распределение скорости, полученное в результате предварительного решения гидродинамической задачи в двумерной области канала со стеклом. Согласно принятой схеме решения, показанной на рис. 3, передача данных из двумерной задачи в трехмерную осуществляется путем задания распределения скорости на входе в канал для решения задачи в трехмерной постановке.

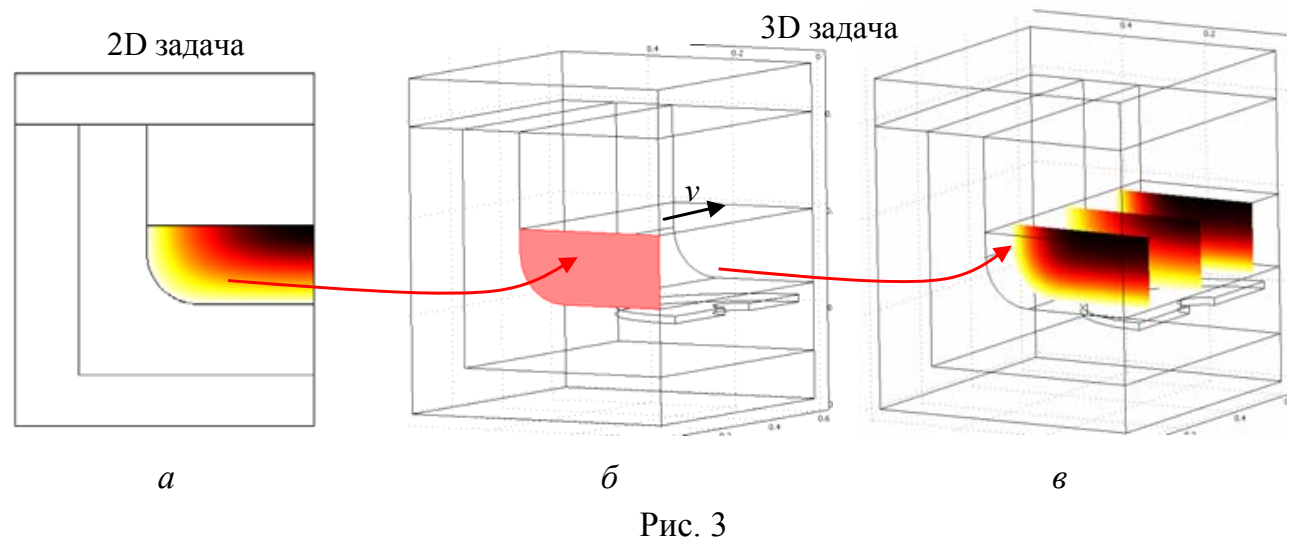


Вспомогательная гидродинамическая задача решается только в подобласти, соответствующей стекломассе, и позволяет найти установившееся движение вязкой несжимаемой жидкости в бесконечно длинном канале согласно [14, уравнение (43)]:

$$
\eta\left(\frac{\partial^{2} \mathbf{v}}{\partial x^{2}}+\frac{\partial^{2} \mathbf{v}}{\partial y^{2}}\right)=\frac{d p}{d z} .
$$

Для двумерной, как и для трехмерной задач приведенные далее граничные условия одинаковы. На поверхности расплава выбирается условие открытой границы, на твердых стенках - отсутствие скольжения $(\mathbf{v}=0)$, на плоскости симметрии - условие симметрии $(\mathbf{n} \cdot \mathbf{v}=0)$. На выходе из канала (только для трехмерной задачи) указывается граница вытекания жидкости.

Математические формулировки электромагнитной и гидродинамической задач показывают, что они связаны электромагнитной силой $\mathbf{F}$, действующей на расплавленное стекло в канале.

Тепловая задача решается на основе дифференциального уравнения:

$$
\rho C_{p} \mathbf{v} \nabla T-\nabla \cdot \lambda \nabla T=Q .
$$

Здесь $\rho, C_{p}, \lambda(T)$ - плотность, удельная теплоемкость и теплопроводность расплавленного стекла, соответственно; $\mathbf{v}$ - вектор скорости движения стекла, распределение которого находится в результате решения гидродинамической задачи (4)-(6); $Q$ - удельная мощность источника тепла, обусловливающая индукционный нагрев стекломассы наведенными токами, вычисляемая как

$$
Q=\frac{\dot{\mathbf{J}} \cdot \stackrel{\mathbf{J}}{*}^{\sigma}}{\sigma}=\operatorname{Re}\left(\dot{J}_{x} \stackrel{*}{E}_{x}+\dot{J}_{y} \stackrel{*}{E}_{y}+\dot{J}_{z} \stackrel{*}{E}_{z}\right),
$$

где $\mathbf{J}$ - плотность наведенного тока; $\sigma$ - электропроводность стекломассы; составляющие напряженности электрического поля равны: $\dot{E}_{x}=-j \omega \dot{A}_{x}, \dot{E}_{y}=-j \omega \dot{A}_{y}, \dot{E}_{z}=-j \omega \dot{A}_{z}$.

Для тепловой задачи на плоскости симметрии и на входной (по отношению к движению стекла) поверхности всей области принимается граничное условие $-\mathbf{n}(-\lambda \nabla T)=0$, на выходной поверхности - такое же условие с указанием на границу вытекания расплава (outlet boundary).

Граничное условие на входе в канал с расплавом определяется по результатам измерений с помощью термопар, размещаемых в стекле, как показано на рис. 4 [8].

На внешних границах расчетной области (показанной на рис. 2) задается условие теплообмена с окружающей средой:

$$
\mathbf{n}(-\lambda \nabla T)=k\left(T-T_{0}\right),
$$

где $k$ - коэффициент теплоотдачи, значения которого различны для различных граничных поверхностей; $T_{0}$ - температура окружающей среды; $\mathbf{n}$ - вектор внешней нормали к границе.

В области водоохлаждаемого индуктора температура полагается равной $T=$ const $=70{ }^{0} \mathrm{C}$.

Как видно из формулировки, тепловая задача связана с электромагнитной посредст-

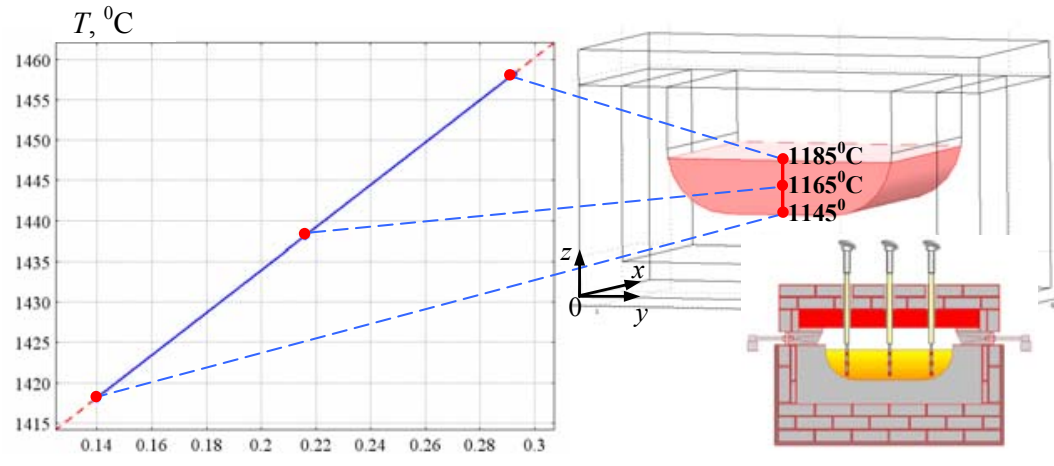

Рис. 4 вом величины $Q$ в (8) (плотности тока $\dot{\mathbf{J}}=-j \omega \sigma \dot{\mathbf{A}}$ в (9)), а с гидродинамической задачей учетом скорости движения стекломассы $\mathbf{v}$ в управляющем уравнении (8).

Таким образом, поставленные электромагнитная, гидродинамическая и тепловая задачи являются взаимосвязанны- 
ми мультифизическими задачами [15] и решались совместно методом конечных элементов в программе Comsol [16]. Конечно-элементное разбиение расчетной области принималось одинаковым для всех задач. Рассмотрение процессов в $1 / 2$ части канала позволило задавать достаточно детальное сеточное разбиение области и вместе с тем сократить время расчетов.

\section{Результаты компьютерного моделирования.}

Исходные данные. Размеры расчетной области (рис. 2) - 1180 х 620 х 692 мм. Длина участка течения расплава - 620 мм. Уровень заполнения канала расплавленным стеклом (высота подобласти 4 на рис. 2) - 152 мм. Скорость движения стекла $-v_{\max }=0,19$ м/мин. Электрофизические характеристики материалов приведены в таблице.

\begin{tabular}{|l|c|c|c|c|}
\hline \multirow{2}{*}{ Характеристики } & \multicolumn{3}{|c|}{ Материал (подобласть согласно рис. 2) } \\
\cline { 2 - 5 } & расплав (4) & канал $(1,3)$ & $\begin{array}{c}\text { термо- } \\
\text { изолятор (2) }\end{array}$ & воздух (5) \\
\hline Плотность $\rho$, кг/м & 2500 & 3100 & 800 & 1000 \\
\hline Теплопроводность $\lambda, \mathrm{BT} /(\mathrm{M} \cdot \mathrm{K}) ;$ & $(6.32)$ & 2,9 & 0,1 & 0,026 \\
\hline Теплоемкость $C_{p}$, Дж/(кг·К) & 730 & 1300 & 1300 & 1000 \\
\hline Электропроводность $\sigma,(\mathrm{Oм} \cdot \mathrm{M})^{-1}$ & 10 & 0 & 0 & 0 \\
\hline Динамическая вязкость $\eta$, Па·с & 10 & - & - & - \\
\hline
\end{tabular}

Заданные частота тока в индукторе $-10^{4}$ Гц и плотности тока $J_{0}=2 \cdot 10^{6} \mathrm{~A} / \mathrm{M}^{2}$. Теплопроводность расплавленного стекла определяется зависимостью [5]

$$
\lambda(T)=1,34+0,0017 \cdot T,
$$

где температура $T$ выражается в ${ }^{0} \mathrm{C}$.

Результаты электромагнитных расчетов представлены на рис. 5. Это распределение магнитной индукции $|\dot{\mathbf{B}}|$ в цвете и стрелками на поверхности расплавленной стекломассы (рис. $5 a$, б) и джоулевых потерь $Q$ в центральном по высоте ( $z=0,346$ м) сечении области с расплавом (рис. 5, в).

Результаты показывают, что магнитное поле $|\dot{\mathbf{B}}|$ в расплаве достигает максимума в области над центральной частью индуктора. Плотность тока $|\mathbf{J}|$, как и джоулевы потери $Q$, также концентрируются в зоне непосредственно над индуктором (рис. 5).

Распределения скорости (в цвете) в двух сечениях выработочного канала по ходу движения стекла показаны на рис. 6 а. Для наглядности отображена область всего канала, а не его половины, как для всех остальных случаев. Показаны неоднородность распределения вектора $\mathbf{V}$ по поперечному сечению канала, наименьшие значения скорости в пристеночных областях и максимальные значения в центре канала вблизи открытой поверхности расплава.

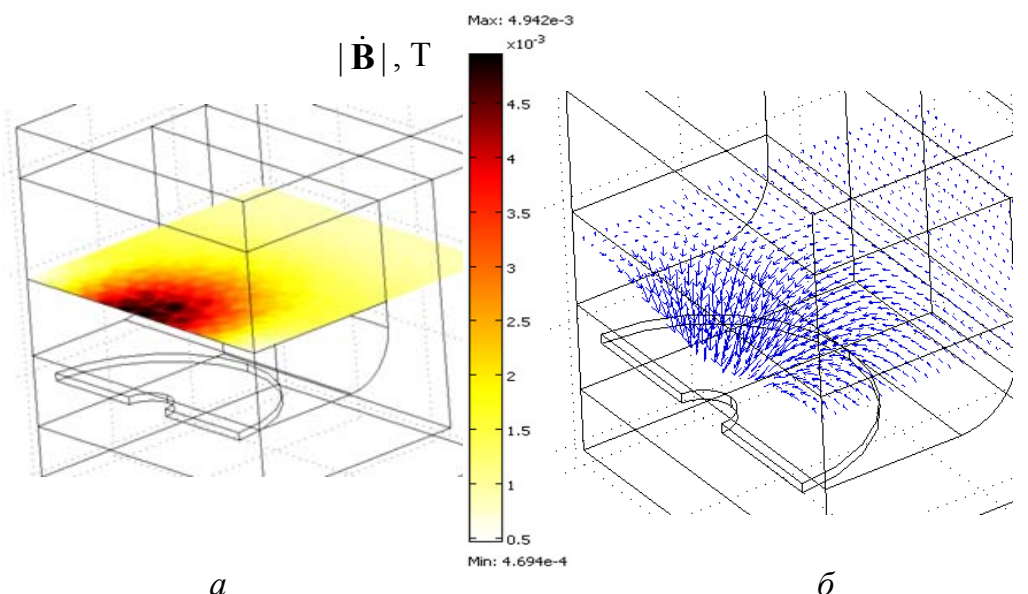

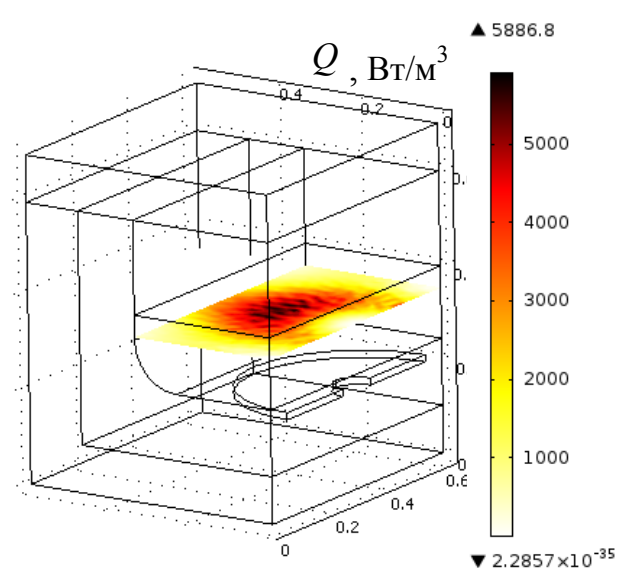

B

Рис. 5 


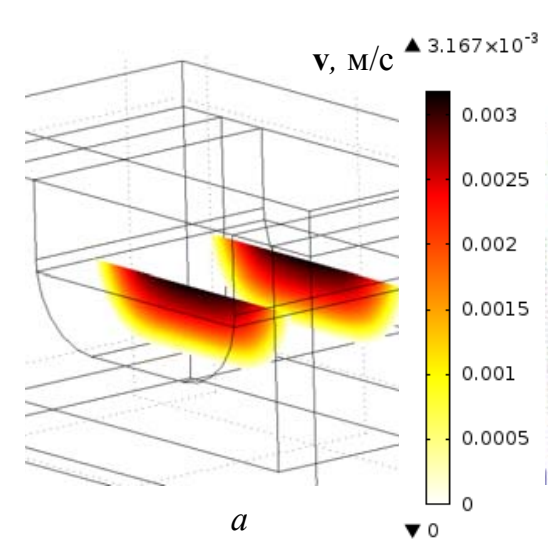

$a$

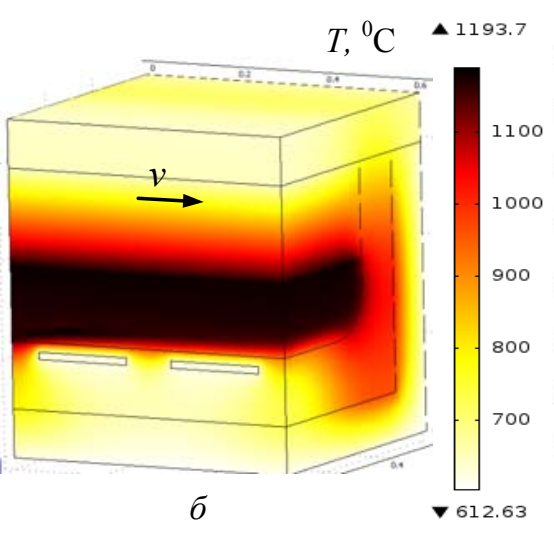

Рис. 6

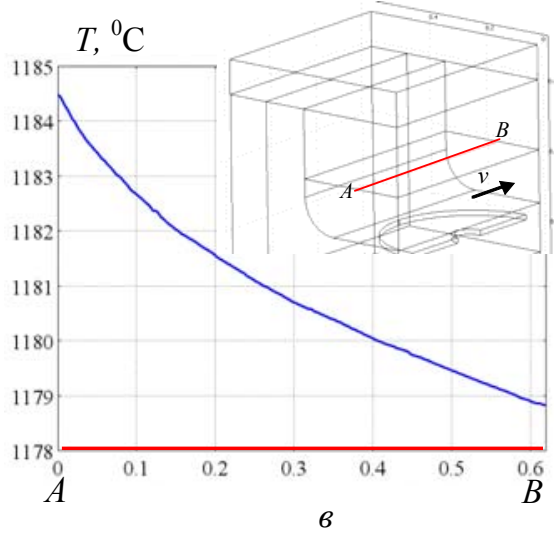

Относительно температуры отметим, что в качестве распределения температуры на входе в область с расплавленным стеклом задавалось полученное экспериментальным путем изменение температуры по линейному закону (рис. 4). В таком случае картина температурного поля во всем объеме расчетной области приведена на рис. 6 б. Заметим, что самые нижние слои расплава имеют более низкую температуру из-за расположенного вблизи водоохлаждаемого индуктора с заданной температурой $70^{\circ} \mathrm{C}$. Уменьшение температуры по ходу движения жидкости из-за близости индуктора показано на рис. 6 в.

Для подтверждения достоверности не только качественных результатов тепловых расчетов, но и количественных результатов для исследуемого выходного канала стекловаренной печи проведено их сравнение с экспериментальными данными из [17]. С этой целью разработана модель выходного канала печи без индуктора. В канале осуществляется охлаждение предварительно нагретой массы стекла согласно данным рис. 4.

Результаты расчетов средней по поверхности мощности теплового потока показаны на рис. 7. Здесь значения теплового потока на единицу поверхности, проходящего через отмеченные границы, для расчетной модели без индуктора и для стекловаренной печи фирмы Saint-Gobain SEFPRO с газовым подогревом [17] приведены на рис. $7 a$ и $\sigma$, соответственно. Расхождение расчетных и экспериментальных данных достигает до 18,2\%.

Отметим, что предлагаемая математическая модель позволяет рассчитывать различные режимы индукционного нагрева при различном расположении индуктора в области канала.

Выводы. Разработаны трехмерная математическая модель и компьютерная методика расчета взаимосвязанных электромагнитных, гидродинамических и тепловых процессов при индукционном нагреве выработочного канала стекловаренной печи. Проведенное сравнение численных и экспериментально полученных значений плотности теплового потока подтверждает достоверность разработанной методики (расхождение результатов на уровне не более $18,2 \%)$.

Предлагаемые математическая и компьютерная модели позволяют определять путем выбора расположения индуктора и его параметров такие режимы нагрева, которые обеспечивают высокую однородность распределения температуры в объеме расплавленного стекла
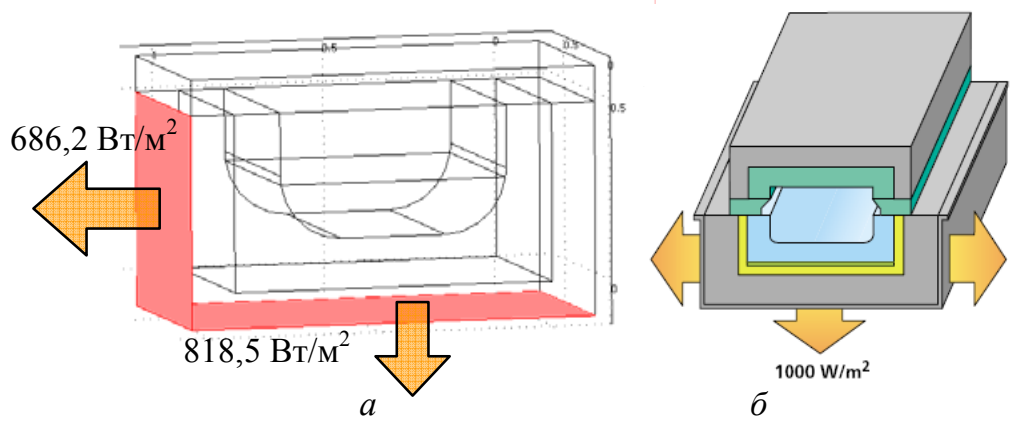

Рис. 7 для дальнейшего изготовления стеклоизделий высокого качества.

Результаты работы подтверждают принципиальную возможность и эффективность использования индукционного нагрева выходного канала стекловаренной печи непрерывного действия. 
1. Гинзбург Д.Б. Стекловаренные печи. Москва: Стройиздат, 1967. 340 с.

2. Гулоян Ю.А. Технология стекла и стеклоизделий. Владимир: Транзит-Икс, 2003. 480 с.

3. Манвелян М.Г., Мелик-Ахназарян А.Ф., Костанян К.А., Налчаджян С.О., Эрзнкян Е.А. Электроварка стекла. Ереван: Армгиз, 1962. 222 с.

4. Плюма Э. Совершенствование и перспективы развития стекловаренных печей. Москва: $1977.80 \mathrm{c.}$

5. Станек Я. Электрическая варка стекла / Под ред. Ю.А. Гулояна. Москва: Легкая индустрия, 1979. 248 с.

6. Doyle P.J. Electricity in the glass industry: 1981-2000. Glass. 1982. V. 59, No. 5. P. 193-199.

7. Ассоциация предприятий стекольной промышленности "Стекло Украины" - http://sklo.kiev.ua/ index.php? $\mathrm{mid}=82$ \&language $=\mathrm{ru}$

8. Groessler J. Thermal homogeneity index - the real truth. - https://www.researchgate.net/publication/ 268054958_Thermal_Homogeneity_Index_-_The_real_truth

9. Захариков Н.А. Теплообменные процессы в стекловаренных печах. Киев: Гостехиздат, 1962.246 с.

10. Товажнянский Л.Л., Кошельник В.М., Соловей В.В., Кошельник А.В. Интегрированные энергосберегающие теплотехнологии в стекольном производстве. Харьков: НТУ "ХПИ", 2008. 628 с.

11. Pilon L., Zhao G., Viskanta R. Three-dimensional flow and thermal structure in glass melting furnaces. Part I: Effect of the net heat flux distribution. Glass Science and Technology. 2002. Vol. 75, No. 2. P. 55-68.

12. Pilon L., Zhao G., Viskanta R. Three-dimensional flow and thermal structure in glass melting furnaces. Part II: Effect of batch and bubbles. Glass Science and Technology. 2002. Vol. 75, No. 3. P. 115-124.

13. Choudhary M.K. Three-dimensional mathematical model for flow and heat transfer in electric glass furnaces. Heat Transfer Engineering. 1985. Vol. 6, No. 4. P. 55-65.

14. Лойцянский Л.Г. Механика жидкости и газай. Москва: Наука, 1978. 736 с.

15. Подольцев А.Д., Кучерявая И.Н. Мультифизическое моделирование в электротехнике. Киев: Ин-т элеткродинамики НАН Украины, 2015. 305 с.

16. Comsol multiphysics modeling and simulation software - http://www.comsol.com/

17. The use of refractories for container glass furnaces. - Буклет фирмы Saint-Gobain SEFPRO, 2009.27 p. http://www.sefpro.com/

УДК $621.365 .5: 004.94$

І.В. Волков, чл.-кор. НАН України, О.Д. Подольцев, докт. техн. наук, І.М. Кучерява, докт. техн. наук Інститут електродинаміки НАН України,

пр. Перемоги, 56, Київ-57, 03057, Україна

\section{ЕЛЕКТРОМАГНІТНІ, ТЕПЛОВІ ТА ГІДРОДИНАМІЧНІ ПРОЦЕСИ ПРИ ІНДУКЦІЙНОМУ НАГРІВІ ВИХІДНОГО КАНАЛУ СКЛОВАРНОЇ ПЕЧІ}

Розроблено і реалізовано математичну модель взаємозалежних електромагнітних, гідродинамічних $і$ теплових процесів у разі індукційного нагрівання вихідного каналу скловарної печі. Тривимірна модель $і$ створена на ї̈ основі комп'ютерна методика дають змогу визначати оптимальні режими нагріву розплавленого скла шляхом вибору розташування індуктора і його параметрів, досягаючи при иььому необхідної температурної однорідності розплаву та його високої якості. Бібл. 17, рис. 7, таблиця.

Ключові слова: електромагнітні, теплові та гідродинамічні процеси, мультифізичні задачі, індукційний нагрів, розплавлене скло, вихідний канал скловарної печі, комп'ютерне моделювання.

\section{I.V. Volkov, O.D. Podoltsev, I.M. Kucheriava}

Institute of Electrodynamics of the National Academy of Sciences of Ukraine,

Peremohy, 56, Kyiv-57, 03057, Ukraine

\section{ELECTROMAGNETIC, THERMAL AND HYDRODYNAMIC PROCESSES AT INDUCTION HEATING OF OUTPUT CHANNEL OF GLASS MELTING FURNACE}

The mathematical model of coupled electromagnetic, hydrodynamic and thermal processes at induction heating of output channel of glass melting furnace is developed and realized. The three-dimensional model and computer technique give a possibility to find the optimal conditions for molten glass heating by right location of inductor, its parameters in order to provide the temperature homogeneity of the glass melt and its high quality. References 17, figures 7, table.

Key words: electromagnetic, thermal and hydrodynamic processes, multiphysics problems, induction heating, molten glass, output channel of glass melting furnace, computer modeling.

1. Ginsburg D.B. Glass melting furnaces. Moskva: Stroiizdat, 1967.340 p.

2. Guloian Yu.A. Technology of glass and glass products. Vladimir: Transit-Iks, 2003. 480 p.

3. Manvenian M.G., Melik-Akhnazarian A.F., Kostanian K.A., Nalchadzhian S.O., Erznkian E.A. Electric melting of glass. Erevan: Armgiz, 1962. 222 p.

4. Pliuma E. Improvement and prospects for development of glass melting furnaces. Moskva: 1977. 80 p.

5. Stanek Ya. Electric melting of glass / Ed. by Yu.A. Guloyan. Moskva: Legkaia industriia, 1979. 248 p.

6. Doyle P.J. Electricity in the glass industry: 1981-2000. Glass. 1982. V. 59, No. 5. P. 193-199.

7. Association of glass-industry plants "Glass of Ukraine" - http://sklo.kiev.ua/index.php?mid=82\& language=ru

8. Groessler J. Thermal homogeneity index - the real truth. - https:/www.researchgate.net/publication/ 268054958_Thermal_Homogeneity_Index_-_The_real_truth 
9. Zajharikov N.A. Heat-exchange processes in glass melting furnaces. Kyiv: Gostekhizdat, 1962. 246 p.

10. Tovazhnianskii L.L., Koshelnik V.M., Solovei V.V., Koshelnik A.V. Integrated energy-efficient thermal technologies in glass production. Harkov: NTU "HPI", 2008. 628 p.

11. Pilon L., Zhao G., Viskanta R. Three-dimensional flow and thermal structure in glass melting furnaces. Part I: Effect of the net heat flux distribution. Glass Science and Technology. 2002. Vol. 75, No. 2. P. 55-68.

12. Pilon L., Zhao G., Viskanta R. Three-dimensional flow and thermal structure in glass melting furnaces. Part II: Effect of batch and bubbles. Glass Science and Technology. 2002. Vol. 75, No. 3. P. 115-124.

13. Choudhary M.K. Three-dimensional mathematical model for flow and heat transfer in electric glass furnaces. Heat Transfer Engineering. 1985. Vol. 6, No. 4. P. 55-65.

14. Loitsianskii L.G. Mechanics of liquid and gases. Moskva: Nauka, 1978. 736 p.

15. Podoltsev A.D., Kucheriava I.M. Multiphysics modeling in electrical engineering. Kyiv: Institute of Electrodynamics, Ukrainian Academy of Sciences, 2015. 305 p.

16. Comsol multiphysics modeling and simulation software - http://www.comsol.com/

17. The use of refractories for container glass furnaces. - Saint-Gobain SEFPRO, 2009. 27 p. http://www.sefpro.com/

Надійшла 05.07.2018

Received 05.07.2018

\title{
УДК 621.314
}

\section{ДОСЛІДЖЕННЯ РЕЗОНАНСНОГО ІНВЕРТОРА ДЛЯ ІНДУКЦІЙНОГО НАГРІВАННЯ 3 СТАБІЛІЗАЦІЕЮ ПОТУЖНОСТІ НАВАНТАЖЕННЯ}

\author{
Г.С. Бслоха", канд. техн. наук, Д.І. Морозов ${ }^{* *}$, канд. техн. наук \\ Донбаський державний технічний університет, \\ м. Лисичанськ, пр. Перемоги, 84.93100, Україна \\ e-mail:pointage13@gmail.com
}

Наведено резонансний інвертор напруги для індукційного нагрівання з стабілізацією потужності навантаження. Керування вихідною потужністю досягається за рахунок зміни форми напруги, щуо подається на резонансний контур. Запропонований принџип керування потужністю дає змогу інвертору працювати на резонансній частоті для всіх рівнів вихідної потужності. Керування температурою нагрівання здійснюється шляхом регулювання потужності навантаження резонансного інвертора. Наведено результати моделювання резонансного інвертора, а також спосіб визначення резонансних характеристик інвертора з використанням аналітичних розрахунків, заснованих на визначенні характеристик за першою гармонікою вихідної напруги. Бібл. 6 , рис. 4.

Ключові слова: резонансний інвертор, індукційне нагрівання, стабілізація потужності.

Введення. Нагрівання металу є розповсюдженим технологічним процесом. Вибір методу нагрівання металу істотно впливає на якість нагрівання. Одним з його методів $є$ індукційне нагрівання, яке широко використовується в промисловості завдяки його перевагам, таким як безпека нагріву, безконтактність й ефективність у порівнянні з іншими класичними методами. Електрична енергія, що подається в індуктор, перетворюється на теплову енергію заготівки через електромагнітне поле без будь-якого фізичного з'єднання з заготівкою. Для отримання бажаного рівня температури на заготівці параметри навантаження мають контролюватися за допомогою електроенергії, що їй передається.

Для індукційного нагрівання використовуються транзисторні або тиристорні резонансні інвертори [1], які за схемотехнікою можуть бути мостові, напівмостові з різними законами керування для забезпечення стабілізації параметрів навантаження, таких як напруга навантаження (для поверхневого гартування), струм навантаження (для максимального нагрівання) або потужність навантаження (для рівномірного нагрівання) [2, 3].

Високочастотне індукційне нагрівання застосовується у різних технологічних операціях, у тому числі й для нагрівання заготівок перед подальшою пластичною деформацією. 